\title{
RESULTS ANALYSIS OF TI6AL4V TITANIUM ALLOY TESTS IN STATIC LOAD CONDITIONS
}

\author{
Karolewska K.*, Ligaj B.**
}

\begin{abstract}
The development of additive manufacturing increased the spectrum of printers from those intended for plastics to those that are designed for metal. Printing in metal allows to create elements of any shape and geometry, which would be difficult or even impossible to perform using conventional manufacturing methods. The aim of the work is to present the test results under static loading conditions of Ti6Al4V alloy produced by $3 D$ printing. The test results obtained under static load conditions of Ti6Al4V material produced by the DMLS additive technology and drawn bar allow to conclude that: yield point $S_{y 0.2}$ for material made using the DMLS technology is higher than the value for the material delivered in the form of a drawn bar by $11.1 \%$, material tensile strength $S_{u}$ for material made using DMLS technology is higher than the value for material delivered in the form of a drawn rod by $11.5 \%$.
\end{abstract}

\section{Keywords: DMLS additive method, Tensile strength, Ti6Al4V titianium alloy, R56400 titanium alloy,} TiAl6V4 titanium alloy.

\section{Introduction}

The technology of 3D printing in metal is gaining popularity due to the possibility to product the elements of any geometry, which is difficult or impossible to obtain with the methods used so far. One of the most commonly used additive methods is Direct Metal Laser Sintering (DMLS). The printing process precedes the 3D model creation on the basis of which the element is manufactured. In the DMLS method, powdered metal is evenly distributed on a mobile working platform, on which a laser beam heats the metal particles causing them to sinter in places consistent with the numerical model.

Structural elements produced by the additive method may contain defects in the structure, forming between successive layers. The residual stress in the printed element may initiate cracks, cause delamination of the material, and may reduce fatigue life. Porosity and other microstructure defects deteriorating the strength properties of elements, which can be minimized by selecting printing parameters (Guzanova et al., 2017).

Due to its mechanical properties and resistance to high temperatures, Ti6Al4V alloy is used in aviation for: turbine engine components, discs, rings, blades, aviation fittings and rocket engine coatings. In medicine, the specified alloy is used to manufacture: joint endoprostheses, elements for anastomosis of bone fragments, in dental prosthetics, cardiac surgery, and interventional cardiology. The use of titanium in medicine results from its biocompatibility with human tissue, as well as its low mass and corrosion resistance (Fig. 1). Elements produced by the use of the additive manufacturing method are subject to variable loads during operation. This impose fatigue life calculations (Ligaj et al., 2018 and Strzelecki et al., 2019), as well as experimental tests in specific environmental conditions (Kałaczyński et al., 2017 and Musiał et al., 2018).

The aim of the paper is to present the tests results under static load condition of Ti6A14V material produced by the DMLS additive method. The scope of work includes the results presentation: geometric measurements of samples made using the DMLS method and the strength tests results under static load conditions. Strength tests were carried out on samples produced by DMLS additive technology and from a drawn bar by turning.

\footnotetext{
* Asst. Prof. Karolina Karolewska: Faculty of Mechanical Engineering, UTP University of Science and Technology in Bydgoszczy, al. Prof. S. Kaliskiego 7, 85-796 Bydgoszcz, PL, e-mail: karolina.karolewska@utp.edu.pl

** Prof. Bogdan Ligaj, PhD.: Faculty of Mechanical Engineering, UTP University of Science and Technology in Bydgoszczy, al. Prof. S. Kaliskiego 7, 85-796 Bydgoszcz, PL, e-mail: bogdan.ligaj@utp.edu.pl
} 

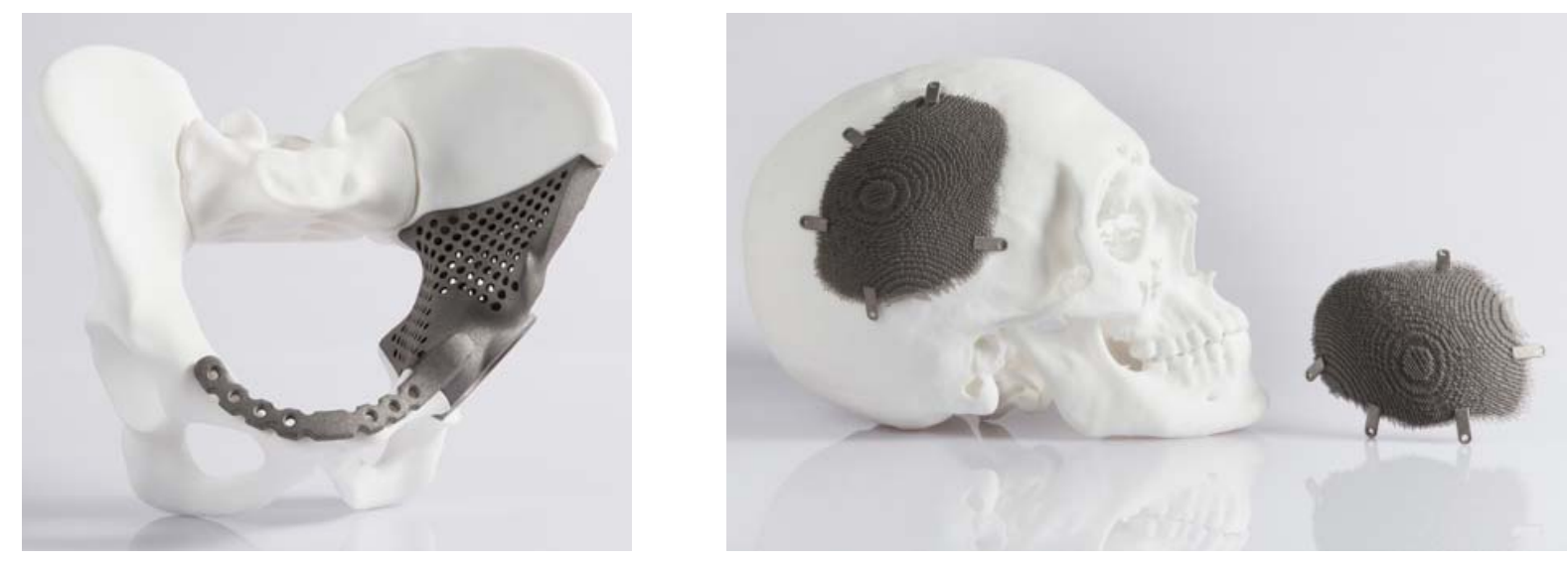

Fig. 1: Implants made in DMLS technology (https://www.eos.info).

\section{Experimental tests}

\subsection{Test samples made with DMLS technology}

The test objects were samples of geometric shape and dimensions shown in Fig. 2. Test samples were made of Ti6Al4V titanium alloy according to ISO 5832 standard. Ti6Al4V alloy belongs to $\alpha+\beta$ two-phase alloys. The occurrence in this material a two-phase structure is the result of the presence in the alloy an appropriate amount of alloying additives that stabilize the $\beta$ phase.

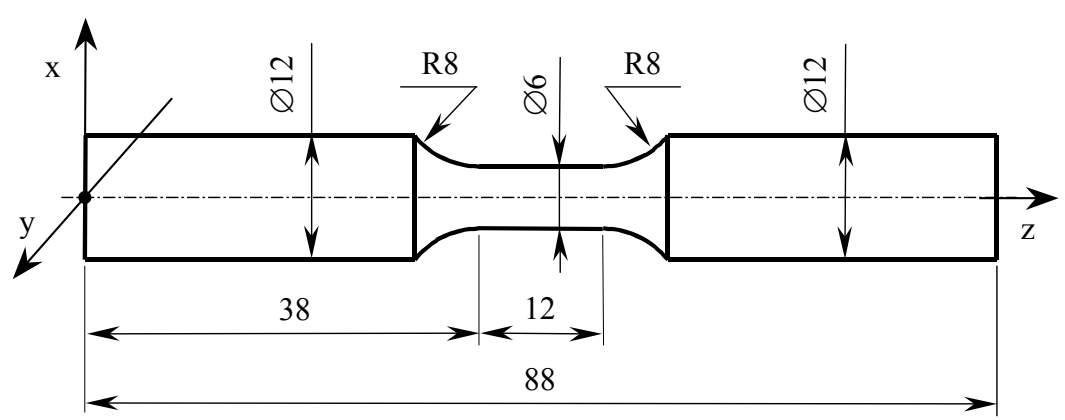

Fig. 2: Test sample made using the DMLS printing method from Ti6Al4V material.

Research samples were printed by the DMLS method on an EOS M280 printer while maintaining the technological parameters:

a) printing direction: along the $\mathrm{Z}$ axis,

b) laser power: $200 \mathrm{~W}$,

c) scanning speed: up to $7 \mathrm{~m} / \mathrm{s}$,

d) minimum layer thickness: $30 \mu \mathrm{m}$.

\subsection{Geometric features measurement}

The samples were assessed for accuracy in the required shape. The measurements were carried out on 10 test objects. The sample measuring part deviations of the roundness were estimated using the Mitutoyo CRYSTA-APEX S574 device. Diameter values and roundness deviation were measured in three sections of the working part. Distance of the specified cross-section from the sample base (Fig. 3).

Tab. 1 presents the results of diameters and roundness deviations measurements in statistic terms using the parameters: mean value, standard deviation, minimum value and maximum value. The listed parameters were determined for 10 samples in three sections.

The measurements of the measuring part diameters show that the samples made using the additive manufacturing method fall within the dimension tolerance field established according to PN-76 / H-04325 $( \pm 0.05 \mathrm{~mm})$. However, their accuracy is not as high as for samples turned from a drawn bar. The distribution analysis of measuring points for individual cross-sections regarding the roundness deviation measurement indicates shape irregularity in relation to the nominal circle (Karolewska et al., 2019). 


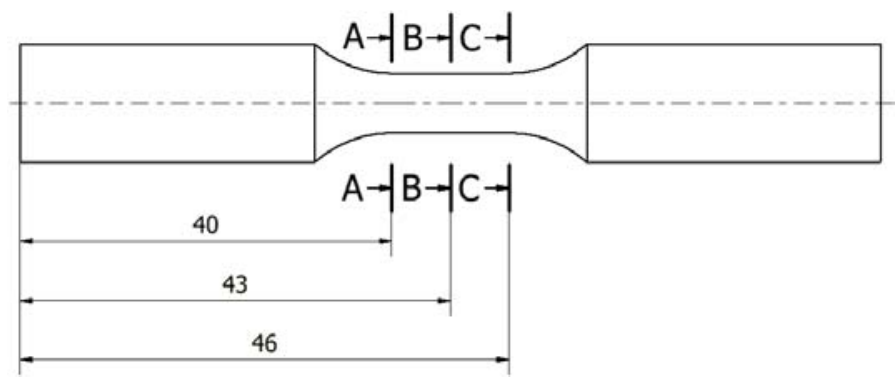

Fig. 3: Test sample with diameters and roundness measuring points marked.

Tab. 1: The roundness and diameter deviation measurement results of the sample measuring part.

\begin{tabular}{|c|c|c|}
\hline \multirow{2}{*}{} & \multicolumn{2}{|c|}{ The sample measuring part parameters } \\
\cline { 2 - 3 } & Diameter & Roundness deviation \\
\cline { 2 - 3 } & $\mathrm{mm}$ & $\mathrm{mm}$ \\
\hline Average value & 5.949 & 0.019 \\
\hline Standard deviation & 0.004 & 0.004 \\
\hline Minimum value & 5.942 & 0.013 \\
\hline Maximum value & 5.958 & 0.027 \\
\hline
\end{tabular}

\subsection{Strength tests under tensile loads}

Tensile strength tests were carried out in accordance with the recommendations of PN-EN ISO 6892-1: 2016 standard. The tests were carried out on an INSTRON 8502 hydraulic testing machine using an extensometer. The control parameter during the tests was a machine piston displacement of $0.05 \mathrm{~mm} / \mathrm{s}$.

An example of a test sample made using DMLS additive technology is shown in Fig. 4a.

a)

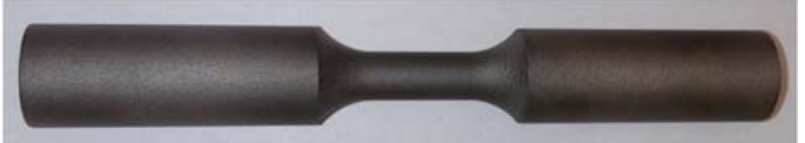

b)

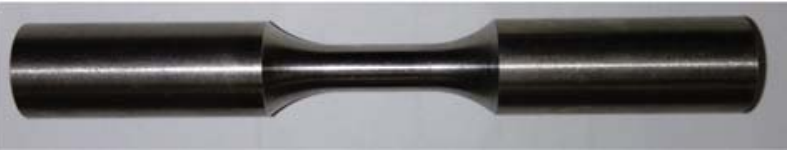

Fig. 4: Physical form of test objects made: a) DMLS additive technology; b) by turning from a drawn bar.

In order to compare the tests results on the Ti6Al4V material produced by the DMLS additive technology, research were also carried out on the material Ti6Al4V delivered in the form of a drawn bar with a diameter of $12 \mathrm{~mm}$. The samples geometrical form manufactured from the rod was in accordance with Fig. 2. The physical object for testing is shown in Fig. 4b. The tests allowed determination of static strength parameters, which are presented in Tab. 2.

Tab. 2: Average values of static strength parameters under tensile loads.

\begin{tabular}{|c|c|c|c|c|c|}
\hline \multirow{2}{*}{ Material production method } & \multicolumn{5}{|c|}{ Static parameters of Ti6A14V material } \\
\cline { 2 - 6 } & $\mathrm{S}_{\mathrm{y} 0,2}$ & $\mathrm{~S}_{\mathrm{u}}$ & $\mathrm{E}$ & $\mathrm{A}$ & $\mathrm{Z}$ \\
\cline { 2 - 6 } & $\mathrm{MPa}$ & $\mathrm{MPa}$ & $\mathrm{MPa}$ & $\%$ & $\%$ \\
\hline DMLS additive technology & 1052 & 1127 & 114510 & 15.5 & 17.3 \\
\hline Drawn bar (turned samples) & 947 & 1010 & 113060 & 29.7 & 38.1 \\
\hline
\end{tabular}

\section{Analysis of tests results and conclusions}

The obtained test results under static loads of Ti6Al4V material produced by DMLS additive technology and from a drawn rod allow to conclude that:

a) yield point $S_{\mathrm{y} 0.2}$ for material made with DMLS technology it is higher than the value for material delivered in the form of a drawn bar by $11.1 \%$, 
b) the material's tensile strength $S_{u}$ for material made with DMLS technology is higher than the value for material delivered in the form of a drawn rod by $11.5 \%$,

c) the elongation of the test sample made of material made using DMLS technology is lower than the value for the material delivered in the form of a drawn bar by $47.0 \%$,

d) the narrowing of the test sample made of material made using DMLS technology is lower than the value for the material supplied in the form of a drawn bar by $54.6 \%$.

Analyzing the samples fractures after breaking, it can be seen that in the specimen made of drawn barin the measuring part, a visible narrowing at the fracture is occurred. The narrowing is not visible on the sample made using DMLS technology. Fig. 5 shows microscopic images of broken samples fractures. In the case of a printed sample (Fig. 5a), the form of damage corresponds to a brittle crack that has initiated from the outer surface on different layers. After damage to the outer section, further damage to the sample occurred along the sintered layers. The form of damage to the sample made of a drawn bar (Fig. 5b) corresponds to breakthroughs for elastic-plastic materials.

a)

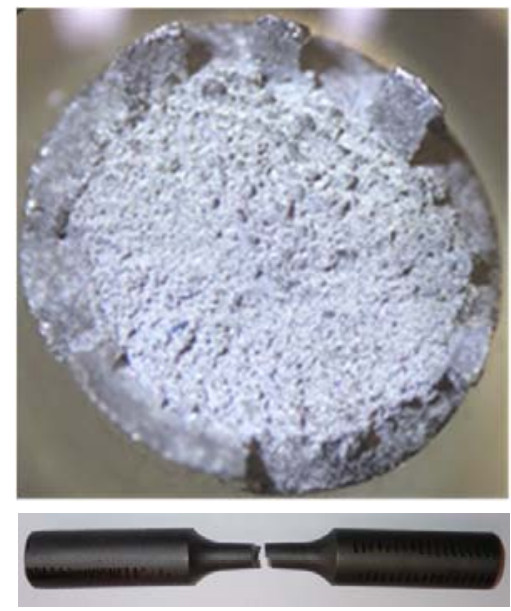

b)

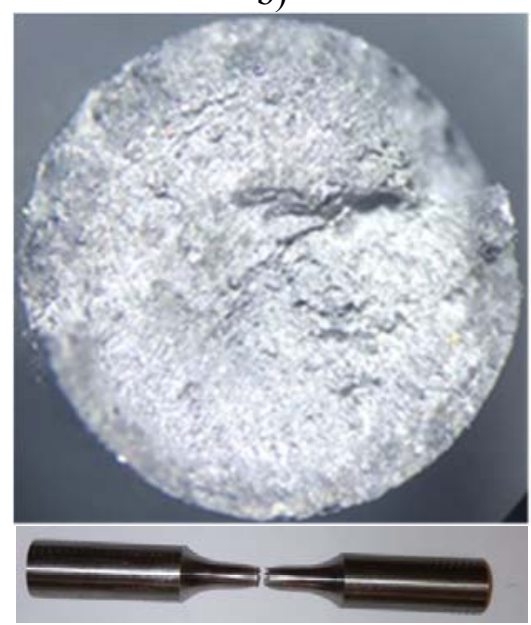

Fig. 5: Microscopic photos of fractures of samples after rupture: a) additive DMLS technology; b) from a drawn bar with a diameter of $12 \mathrm{~mm}$ (turned samples).

From experimental and literature studies (Benedetti et al., 2017) it follows that Ti6Al4V material produced by the DMLS additive technology is characterized by a higher value of strength $S_{u}$ and the conventional yield strength $\mathrm{S}_{\mathrm{y} 0.2}$ than the material produced by the traditional (metallurgical) method.

\section{References}

Benedetti, M., Torresani, E., Leoni, M., Fontanari, V., Bandini, M., Pederzolli, C., Potrich, C. (2017) The effect of post-sintering treatments on the fatigue and biological behavior of Ti-6Al-4V ELI parts made by selective laser melting. Journal of the Mechanical Behavior of Biomedical materials, pp. 2995-3006.

Guzanova, A., Izarikova, G., Brezinova, J., Zivack, J., Draganovska, D., Hudak R. (2017) Influence of build orientation, heat treatment, and laser power on the hardness of Ti6Al4V manufactured using the DMLS process, Metals, 7, no. 318 .

Karolewska, K., Ligaj, B. (2019) Comparison Analysis of Titanium Alloy Ti6Al4V Produced by Metallurgical and 3D Printing Method, Scientific Session on Applied Mechanics X, Book Series: AIP Conference Proceedings, vol. 2077, Article Number: UNSP 020025, doi: 10.1063/1.5091886.

Kałaczyński, T., Łukasiewicz, M., Musiał, J., Polasik, R., Szczutkowski, M., Dluhunovych, N., Wilczarska, J., Kasprowicz, T. (2018) Analysis of the diagnostic potential research thermovision in the technical state of combustion engine injectors assessment. $24^{\text {th }}$ International Conference on Engineering Mechanics, Engineering Mechanics vol. 24, pp. 357-360.

Ligaj, B., Karolewska, K. (2018) Fatigue Life Calculations of Structural Elements by Means of Equivalent Load Spectrum and Material Properties for LCF and HCF, Fatigue Failure and Fracture Mechanics XXVII, Book Series: AIP Conference Proceedings, vol. 2028, Article Number: UNSP 020007, doi:10.1063/1.5066397.

Musiał, J., Szczutkowski, M., Polasik, R., Kałaczyński, T. (2017) The influence of hardness of cooperating elements on performance parameters of rolling kinematic pairs. Proceedings of $58^{\text {th }}$ International Conference of Machine Design Departments - ICMD 2017 pp. 260-265.

Strzelecki, P., Mazurkiewicz, A., Musiał, J., Tomaszewski, T., Słomion, M. (2019) Fatigue Life for Different Stress Concentration Factors for Stainless Steel 1.4301. Materials 12/2019, pp. 1-9. 